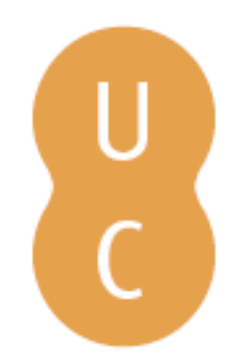

\title{
nombalina
}

\section{Confianza y deliberación: las condiciones éticas de la participación democrática}

\author{
Autor(es): Reigadas, María Cristina
}

Publicado por: Imprensa da Universidade de Coimbra

URL

persistente: URI:http://hdl.handle.net/10316.2/31318

DOI: $\quad$ DOI:http://dx.doi.org/10.14195/978-989-26-0222-6_2

Accessed : $\quad$ 26-Apr-2023 10:53:01

A navegação consulta e descarregamento dos títulos inseridos nas Bibliotecas Digitais UC Digitalis, UC Pombalina e UC Impactum, pressupõem a aceitação plena e sem reservas dos Termos e Condições de Uso destas Bibliotecas Digitais, disponíveis em https://digitalis.uc.pt/pt-pt/termos.

Conforme exposto nos referidos Termos e Condições de Uso, o descarregamento de títulos de acesso restrito requer uma licença válida de autorização devendo o utilizador aceder ao(s) documento(s) a partir de um endereço de IP da instituição detentora da supramencionada licença.

Ao utilizador é apenas permitido o descarregamento para uso pessoal, pelo que o emprego do(s) título(s) descarregado(s) para outro fim, designadamente comercial, carece de autorização do respetivo autor ou editor da obra.

Na medida em que todas as obras da UC Digitalis se encontram protegidas pelo Código do Direito de Autor e Direitos Conexos e demais legislação aplicável, toda a cópia, parcial ou total, deste documento, nos casos em que é legalmente admitida, deverá conter ou fazer-se acompanhar por este aviso.

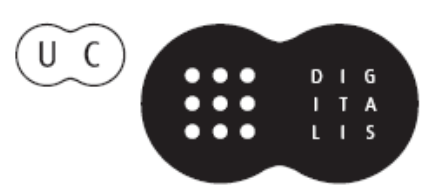


Sílvia Portugal

Paulo Henrique Martins

Organização

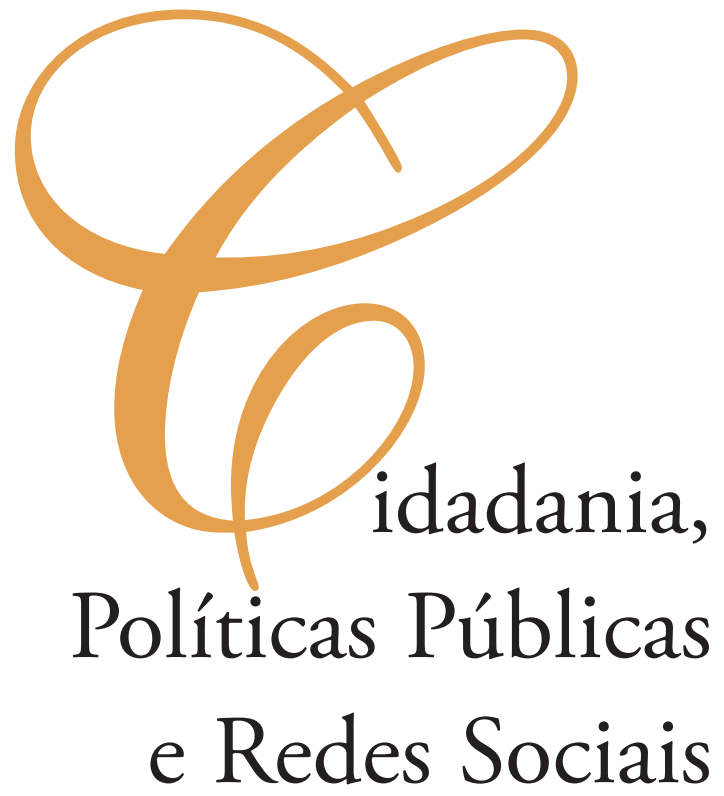


María Cristina Reigadas

\section{CONFIANZA Y DELIBERACIÓN: LAS CONDICIONES ÉTICAS DE LA PARTICIPACIÓN DEMOCRÁTICA}

\section{Introducción}

A más de veinte años de recuperadas las instituciones democráticas en América Latina, el debate político gira hoy en torno a las cuestiones relativas a su consolidación y calidad institucional tanto como respecto a las bases sociales de los procesos de democratización. Visiones institucionalistas y populistas o neopopulistas compiten por hegemonizar el campo interpretativo. El retorno del estado se sucede al de la sociedad civil y los sujetos de sus respectivas esferas pujan por resignificar el sentido de la crisis de la política y de lo político. Gobernantes, funcionarios, administradores y partidos políticos, por un lado, y viejos y nuevos movimientos sociales, ONG's y asociaciones voluntarias, por otro, se reflejan y acusan mutuamente: los unos, de querer robarles la función, el rol y la clientela. Los otros, de corruptos, poco transparentes e ineficaces, no sólo en la gestión, sino en su incapacidad para formular objetivos transformadores. Sin embargo, la disputa no logra soslayar la cuestión de base: los modelos tradicionales de acumulación de poder social y político, la toma de decisiones, los tipos de liderazgo, la formulación, ejecución y evaluación de las políticas públicas estatales tanto como los servicios realizados por las organizaciones comunitarias, son poco democráticos. Importan los resultados más que el modo en que éstos se construyen e importa muy poco si los sujetos "destinatarios" se transforman, aprenden y crecen en autonomía y poder decisorio.

Por otra parte, los debates sobre la construcción y calidad de la democracia en la región se dan hoy en un contexto de marcada desconfianza y desvalorización de la democracia representativa y, paradójicamente, de baja participación ciudadana.

Respecto de la primera cuestión, ${ }^{1}$ los datos son alarmantes. En Argentina (que no constituye un caso aislado en Latinoamérica) más de la mitad de la población estaría dispuesta a aceptar un régimen autoritario si se garantizara un mejoramiento económico. Mientras que un $43 \%$ respalda a la democracia, el $30 \%$ es ambivalente y el 26,5 tiene un punto de vista no democrático. A pesar de los altos niveles de afiliación política (3 millones de afiliados), hay escasa participación en actividades partidarias: sólo un 3\% participa de ellas. Solamente el $29 \%$ de los encuestados considera que hay democracia cuando se garantiza el voto y la libertad de expresión. Por otra parte, las relaciones paternalistas y clientelares no parecen

1 Véase Informe del Banco Mundial (2002). Ver también Reigadas (2004). 
haber sido superadas en la política argentina. La mayoría de los argentinos culpabilizan al Estado de su ignorancia respecto de sus deberes y se consideran niños inmaduros para vivir en democracia. Creen que los cambios deben venir desde arriba, desde el Estado pero, a la vez, lamentan la carencia de poder de éste.

En cuanto a los índices de participación ciudadana son significativamente más bajos que en Europa Occidental, Australia y Estados Unidos², siendo menor aún el índice de confianza que constituye un aspecto decisivo en la construcción de una sociedad democrática. En la Argentina solamente un 23\% confía en sus compatriotas y menos personas aún en los poderes públicos. Según una encuesta de la Universidad de Belgrano, un tercio de la población aceptaría liderazgos fuertes si la gestión produce los resultados esperados y, por los mismos motivos, otro tercio toleraría la corrupción y el clientelismo. Finalmente, la Argentina ha desarrollado una cultura de la sospecha y de la confusión, en la cual el cumplimiento de los deberes y las normas suele estar identificado con el disciplinamiento autoritario, la corrupción tolerada y el éxito es considerado como legitimador de la conducta individual y colectiva.

En síntesis, si bien se han multiplicado las acciones de la sociedad civil (movimientos sociales, organizaciones comunitarias, etc.), el índice de participación ciudadana es aún muy bajo y tiende a descender. ${ }^{3}$ Segundo, las prácticas de los distintos actores involucrados (provengan del campo social, político o gubernamental) muchas veces no son democráticas y tercero, la baja valoración de la democracia en la región sin duda tiene que ver con lo que buena parte de la ciudadanía considera sus muy escasos rendimientos. ${ }^{4}$ En suma, (1) participación ciudadana, (2) calidad de la democracia y (3) valoración de la democracia constituyen un entramado ético-político y social al que debemos interrogar a fin de salir del atolladero que pendularmente nos ha hecho creer que con la democracia sola se come o que, dado que no nos garantiza comer, bien podríamos prescindir de ella.

Sin duda que los obstáculos que operan para fortalecer y profundizar la democracia son diversos, siendo muy importante el impacto de las condiciones que impone la economía global y la política internacional y la carga histórica que al respecto pesa sobre el continente y que, por cierto, no puede ser reducida a las crisis de las últimas décadas. En cuanto a los factores culturales, se ha destacado el peso del autoritarismo, pero se han descuidado otros igualmente fundamentales, como la negación y olvido de la historia, el afán refundacionalista, la mímesis y, en el caso argentino, el excepcionalismo (Reigadas, 2000).

Por otra parte, se observa que las explicaciones económicas, políticas y/o culturales de nuestras dificultades suelen naturalizar las causas tanto como atribuirlas siempre a agentes externos. En última instancia y aún cuando cíclicamente hay autoculpación y sentimientos

${ }^{2}$ El Índice de Participación Ciudadana (2005) muestra un descenso en la participación en nuestro país en relación a ańos anteriores. Hay que relacionar el momento más alto de la participación con la crisis (y postcrisis) del 2001, tanto con la multiplicación de la solidaridad ante situaciones de urgencia y emergencia económico-social como con necesidades vinculadas a la defensa de derechos: troquistas, ahorristas defraudados, familiares de víctimas del gatillo fácil y de la seguridad.

3 Véase el Informe de Participación Ciudadana en América Latina (2005), realizado en 8 países de América Latina por la RID (Red Interamericana para la Democracia), Fundación Conciencia, GADIS (Grupo de Análisis y Desarrollo Institucional y Social) y FINES (Fundación de Investigaciones Económicas y Sociales).

4 Véase PNUD/Argentina (2004 y 2005), Encuesta “Democracia, corrupción y clientelismo” (2003), PNUD (2004). 
de impotencia, la explicación en última instancia está dada por la acción manipuladora de "los otros".

Finalmente, que América Latina tenga 150 millones de pobres y 225 millones de indigentes y sea el continente con mayores desigualdades distributivas del planeta, tal como lo certifica que el 10\% más rico tiene el 40 al $47 \%$ del ingreso y el $20 \%$ más pobre del 2 al $4 \%$, constituye un desafío singular para la consolidación de la democracia.

Mientras que algunos se cuestionan cuanta democracia puede sostenerse en tales condiciones, otros, por el contrario, consideran que hay un nexo entre pobreza y debilidad de la democracia y que su fortalecimiento constituye un factor decisivo para un desarrollo humano con justicia y equidad.

Sin embargo, las críticas y los déficits de la democracia en la región no constituyen un obstáculo para la defensa de la participación ciudadana en las cuestiones públicas, habida cuenta de que la fuerza de la democracia participativa, que combina mecanismos de la democracia representativa con otros de la democracia directa, reside en su defensa irrestricta de la soberanía popular. La participación ciudadana recentra la acción colectiva en la sociedad civil, que recupera su protagonismo y carácter público, y cuestiona en los hechos el monopolio estadocéntrico de las política.

Pero si bien hay consenso acerca de la legitimidad de la participación ciudadana, lejos se está de haberlo alcanzado cuando hay que definir qué es lo que hace democrática a la participación popular, ya que no toda participación es democrática y que más participación no asegura más democracia.

$\mathrm{Al}$ respecto, Jürgen Habermas y Amartya Sen, entre otros y por distintos caminos, han señalado que una política democrática no puede reducirse a la agregación de intereses ni a la toma de decisiones producto de la hegemonía, ni al reparto de bienes o al principio de beneficiar siempre a los desaventajados, ni tampoco fundarse en decisiones técnicas, en valores supuestamente compartidos o en la sabiduría del gobernante. Una política democrática debe asegurar la construcción de una voluntad y opinión pública racionalmente fundada. Son los debates públicos y los acuerdos racionalmente motivados que de ellos emanan lo que otorga cualidad democrática a la participación popular.

En este sentido, las teorías de la democracia deliberativa proponen un camino más complejo y más lento, pero más sólido y eficaz para promover la inclusión con igualdad y la capacidad de decidir autónomamente los propios proyectos de vida individuales y colectivos. Es por cierto su práctica habitual en distintas instituciones formales e informales lo que hace de ella, como quería Dewey, una forma de vida.

\section{Las difíciles relaciones entre ética y política}

Difícilmente pueda pensarse la política desvinculada de la ética y mucho menos si se la define a partir de la deliberación. Sin embargo, las relaciones entre ambas no son sencillas y la separación entre ambas se remonta a los inicios mismos de la modernidad. Hay que subrayar que las consecuencias de esta disociación han sido y son nefastas para el desarrollo de la vida social, máxime en situaciones de colonialismo y poscolonialismo, ya que cuando no se posee la fuerza ni el poder, la ética constituye un poderoso aliado de la liberación. Claro que no cualquier ética, y ese es el punto que es necesario discutir. En especial para unas ciencias sociales habitualmente ciegas para las cuestiones morales y en 
las cuales el estructuralismo y postestructuralismo han dificultado la comprensión de las cuestiones microsociológicas ligadas al rol del respeto y la reciprocidad, del reconocimiento y la confianza mutua, del diálogo y la conversación, en cuanto medios informales de coordinación social y fundamentos insoslayables del funcionamiento de la economía y de las instituciones políticas.

La propia mainstream de nuestras ciencias sociales y la falta de interacción entre filósofos y cientistas sociales es sin duda uno de los motivos por los cuales la ética ha sido restringida a sus aspectos estrictamente prescriptivos y considerada ajena a las duras realidades del poder. Y si bien hoy ha renacido un fuerte interés por ella, que se manifiesta en oficinas y comités de ética, empresas y foros e iniciativas gubernamentales y no gubernamentales, éste suele expresarse en discursos moralizantes y vagorosas apelación a los "valores" que confirman la desconfianza de los científicos sociales en ella. Estas recientes apelaciones a la ética más allá de las intenciones - suelen estar al servicio de complejos y oscuros intereses, y finalmente funcionan como boomerangs, que neutralizan y/o domestican su potencial crítico.

De este modo, las visiones hegemónicas de la política y de la ética ratifican su divorcio: entre la política como pura facticidad del poder y la ética como discurso abstracto no parece haber más que perversa complicidad, pero nunca un vínculo mutuamente enriquecedor y un límite para los excesos.

Sin embargo, la ética está en la raíz misma de una política democrática orientada por ideales emancipatorios y en esa medida, posee una insoslayable materialidad para la construcción de la vida social, ya que no hay cambio social imaginable sin la activa disposición de los sujetos a la autotransformación y a la cooperación.

Siguiendo a Habermas, distingo dos sentidos o aspectos de lo ético, claves para pensar la vida democrática: uno, la ética en cuanto ámbito de las actitudes, significaciones y valores encarnados en prácticas sociales y la ética en cuanto punto de vista moral universalista. $\mathrm{Al}$ primero, corresponden las cuestiones evaluativos propias de las formas de vida, ancladas siempre en contextos histórico-culturales concretos y necesariamente plurales en las sociedades complejas. Mientras que la ética es siempre necesariamente singular, el punto de vista moral nos abre a la dimensión de la universalidad en la medida en que constituye un procedimiento intersubjetivo discursivo que exige la universalización de intereses, lo cual obliga a los participantes a trascender el contexto social y particular de su propia forma de vida y adoptar la perspectiva de todos los posibles afectados. Si las cuestiones ético-evaluativas corresponden, siempre, al ámbito de los contextos histórico-culturales singulares, las cuestiones morales expresan las pretensiones universalistas de justicia. Ambos están estrechamente entrelazados tanto en las comunicaciones de la vida cotidiana como en los discursos prácticos. $\mathrm{Al}$ respecto, Habermas afirma

\footnotetext{
"Sin la irrestricta libertad individual que representa la capacidad de tomar postura frente a pretensiones de validez susceptibles de crítica, un asentimiento tácticamente obtenido no puede tener verdaderamente carácter general; sin la capacidad de cada uno de ponerse solidariamente en el lugar del otro no puede llegarse en absoluto a una solución que merezca el asentimiento general. El proceso de formación discursiva de la voluntad colectiva da cuenta de la íntirna conexión de ambos aspectos: de la autonomía de individuos incanjeables y de su inserción en formas de vida intersubjetivamente compartidas. Los iguales derechos de los individuos y el igual respeto por su dignidad personal vienen sostenidos por una red de relaciones interpersonales y de relaciones de reconocimiento recíproco" (Habermas, 1991).
} 
Es así que la participación democrática conjuga, por un lado, una ética de las relaciones interpersonales basada en el respeto, la solidaridad, el reconocimiento y la confianza y un punto de vista moral que exige someter las propias posiciones a crítica y ser capaz de modificarlas en el transcurso de un proceso de generalización de intereses. Este constituye un auténtico proceso de aprendizajes mutuos en la medida en que surge del intercambio de posiciones y perspectivas, de la adopción del punto de vista del otro y del distanciamiento respecto de los propios intereses y valores.

\section{La confianza}

El creciente interés por la cuestión de la confianza - piedra de toque del lazo social - y sobre la deliberación - piedra legitimatoria de la acción democrática -, y por el nexo entre ambas y democracia, está en relación directa con el aumento de la incertidumbre, del riesgo, de la complejidad y el pluralismo valorativo de la sociedad contemporánea y con la intensificación y multiplicación de los intercambios entre personas, bienes y mensajes producidos por los procesos de globalización, que han precarizado los lazos sociales al dislocar identidades, achicar distancias y volatilizar tiempos.

Basta mencionar dos ejemplos. Uno, la necesidad de relocalización y territorialización de las prácticas sociales, frente a los temores surgidos ante la licuación e intercambiabilidad de las experiencias y el temor a la disolución del sí mismo en un vagoroso y por momentos inasible 'global'. Sin embargo, lo local no es ya mera y solamente local, identificado con el territorio, sino una construcción compleja producto de múltiples acciones y retro-acciones que operan en diferentes tiempos y escalas espaciales.

Dos, y en relación a los sujetos de la participación democrática, el recelo respecto de los lazos impersonales y/o indirectos entre individuos, grupos y redes y, en general al 'sistema', lleva a ubicar reductivamente el lugar 'propio' de la democracia en el cara a cara de los lazos de familiaridad, vecindad y amistad. Sin embargo, la sociabilidad primaria no es el único modelo de democracia ni tampoco su seguro garante. No es el cara a cara y/o los vínculos directos y presenciales (¿cómo definir, por ejemplo, los vínculos internéticos?) lo que genera espacios democráticos, sino aquello que cumple con lo que de ella se espera: el cuidado y la acción solidaria fundados en consideraciones de justicia. Sabido es, por otra parte, que éstos vínculos no se dan "natural" o "espontáneamente" en dichos núcleos primarios y que la confianza básica indispensable para generar lazos sociales democráticos requiere una laboriosa construcción que pone en juego valores tales como decir la verdad, cumplir las promesas y trato equitativo, imparcial y neutro (Offe, 1999) que, obviamente, pueden o no hallarse en distintos tipos de instituciones, incluyendo la familia y la vecindad y la escuela.

$\mathrm{Al}$ respecto Offe sostiene que la construcción de confianza implica procesos reflexivos y abstractos, mediados por reglas institucionales que, finalmente, siempre dependen para su viabilidad de la disposición a la comprensión y al sostenimiento de los que están involucrados en ellas. En este sentido, siempre confiamos en personas, dado que cuando lo hacemos en instituciones, es a través de quiénes están encargados de cumplir los valores presentes en las reglas que rigen aquéllas. Por ello, no se trata de privilegiar un tipo de sociabilidad a otro, suponiendo, por ejemplo, que la sociabilidad primaria es más apta para la democracia. Si la democracia depende de la calidad y tipo de vínculos -y éstos residen en el ethos y la 
ética de los grupos-, éstos entonces son independientes del tipo de sociabilidad: en todo tipo de relaciones sociales se puede ser mendaz, incumplir promesas y ser parcial e injusto.

Pero el hecho de cuestionar el carácter necesariamente democrático y/o más apropiadamente democrático de la vida familiar y vecinal, no implica desconocer que estas instituciones son, en otro sentido, su cuna, ya que difícilmente pueda haber democracia en una sociedad cuyas prácticas sociales cotidianas no lo sean. Dónde la familia es autoritaria, dónde la amistad es mafiosa, donde la vecindad se convierte en un guetto al que poco le importan los demás, difícilmente crezca la democracia. Esto es a lo que Dewey apuntaba cuando sostenía que la democracia es un estilo de vida que, como tal debe cultivarse desde la temprana edad y en las instituciones primarias. No es el 'cara a cara' lo que garantiza la democracia, sino la construcción de hábitos de respeto, reconocimiento y confianza mutua. Tampoco el traslado de las prácticas democráticas de una esfera a otra (de las instituciones familiares o de las asociaciones de la sociedad civil a las instituciones políticas, por ejemplo) es automático, ni hay tampoco entre éstas una relación causal, aún cuando difícilmente haya instituciones democráticas en sociedades cuyas prácticas democráticas no lo sean.

Por otra parte y más allá de los vínculos con iguales -lazos aglutinantes, en términos de las teorías del capital social-, la democracia requiere generar vínculos con individuos y grupos diferentes y lejanos. Aprender con extraños (tal como también caracterizaba Dewey a la democracia) exige desarrollar vínculos de confianza.

Para Seligman (1997) dichos vínculos en el mundo moderno se fundan en la figura del contrato social. Este surge por un acto de confianza que obliga mutuamente al cumplimiento de promesas y une a las personas en una comunidad moral. Siguiendo a Giddens y a Luhmann (aunque en un sentido diferente), distingue confianza (trust) y confiabilidad (confiden$c e$ ) y define a ésta última en relación al conocimiento pasado y a las anticipaciones futuras; hay confidence cuando contamos con que el otro cumplirá su rol y que los sistemas abstractos funcionarán. Por cierto que es trust la que interesa para la construcción de la democracia. Esta, en razón de la incertidumbre que la habita, necesita para su funcionamiento el impulso a asumir un riesgo (confianza). En este sentido, uno confía cuando no sabe, cuando no conoce los motivos del otro, cuando se enfrenta a la 'otredad" del otro. La confianza se distingue también de la fe o creencia por cuanto surge de la interacción y es una función de reciprocidad posibilitada por los espacios que abren el juego mutuo de las expectativas de rol.

Por cierto que hay otras perspectivas sobre la confianza que, a diferencia de ésta, subrayan su dimensión instrumental. Warren (1999) advierte que si bien la democracia se funda en un acto de desconfianza hacia la autoridad, no puede prescindir de ella, dado que asegura la gobernabilidad y alivia las cargas de la decisión política. Así, confianza y democracia son modos diferentes pero complementarios de tomar decisiones y organizar acciones colectivas e instrumentos orientados a disminuir amenazas (el otro es fuente potencial de daño) y conflicto (el otro es portador de intereses antagónicos), y reducir la complejidad. Según esta interpretación, la confianza abreviaría las decisiones tornando prescindible el momento deliberativo, que por cierto requiere información, tiempo y coordinación de la cooperación social.

Hardin (1999) profundiza esta visión instrumental de la confianza y la analiza desde la teoría de la decisión racional que supone que los individuos buscan maximizar sus preferencias y economizar en el esfuerzo de ganar la información necesaria para saber que curso de acción lo logrará. Sin embargo, desde la perspectiva de la elección racional la confianza asume un carácter paradojal, ya que, por un lado, disminuye el costo de la información 
y aumenta los beneficios de la cooperación, pero, por el otro, los que confían parecerían elegir irracionalmente aumentar su vulnerabilidad.

Estas interpretaciones de la confianza parten correctamente de la naturaleza vulnerable del ser humano, máxime en los contextos de interdependencia, incertidumbre y complejidad contemporáneos, pero extraen conclusiones equivocadas al presuponer que el otro constituye, básicamente, una amenaza. Para este enfoque, la confianza es un cálculo de intereses y de reducción del riesgo antes que un proceso de comunicación social.

Otras perspectivas, como las de Foley y Diani (2001), más cercanas al contextualismo de Bourdieu y Coleman, afirman que si bien no hay duda de que la confianza es crucial para muchas relaciones sociales, tampoco hay suficiente evidencia de que confiar en general sea un índice de la salud de la democracia o de logros económicos. Para ellos, la confianza social no es el lubricante universal que aceita las ruedas de la cooperación sino el resultado de un sistema económico, político y social que funciona bien para algunos y por lo tanto, la consideración de la desigualdad en la distribución de recursos no puede estar ausente en el análisis de su construcción.

Sin duda se trata de tres posiciones diferentes que subrayan distintos aspectos o dimensiones de la confianza: en el caso de Warren y de Hardin, el papel del cálculo individual en la acción colectiva, en el de Seligman, el de los valores construidos en las prácticas intersubjetivas y, en el último, el papel determinante del contexto y las estructuras sociales. Quizás estos diferentes puntos de vista no sean necesariamente excluyentes: individuos y grupos se encuentran fuertemente enraizados en estructuras desde las cuales calculan, luchan y producen sentidos y valores. En todo caso y más allá de la perspectiva privilegiada, la confianza constituye un elemento esencial para la existencia, continuidad y "éxito" de la vida social. Lejos de ser naturalizada se construye mediante procesos reflexivos (Offe), que requieren tiempo para transformarse en hábitos. Estos hábitos de confianza, intersubjetivamente construidos y fundados en procesos comunicativos (y no solamente "hábitos del corazón" o recursos para reducir la complejidad sistémica) son los que posibilitan que la democracia funcione. Si de algo trata la confianza es, paradójicamente, acerca de cómo construir el vínculo social en ausencia de fe. Si, como sostuvo Nietzsche, somos animales que hacemos promesas, confiar y ser confiado es esencial en la construcción de la vida humana y la confianza constituye el presupuesto del lazo social y de todo proceso comunicativo.

Resumiendo: la participación democrática debe redefinirse teniendo en cuenta los contextos globalizados, complejos y plurales, y su dimensión ética, en especial aquellas disposiciones que, como la confianza, vehiculizan valores de igualdad y libertad mediante el juego de expectativas mutuas que generan. La confianza pública, lejos de ser una fácil prolongación de la confianza básica o análoga a la confianza intersubjetiva, debe ser construida reflexivamente y según reglas. En este sentido, no es un acto "irracional”, o producto de la fe, sino una disposición que vehiculiza valores de igualdad y libertad, constituyendo así la condición necesaria, aunque no suficiente de la democracia. Una vez establecido el juego del reconocimiento y confianza mutua hay que argumentar y dar razones acerca de las decisiones que atañen a las cuestiones públicas.

\section{La deliberación}

Por cierto que las prácticas deliberativas y los debates previos a la toma de decisiones en las cuestiones públicas constituye parte inalienable de la doctrina democrática. Sin embar- 
go, no sólo en la práctica y por razones de poder y de urgencias la deliberación languidece en la mayoría de las sociedades que se definen como democráticas. También la teoría ha intentado mostrar que los ajustes sistémicos, las decisiones de las élites políticas y/o tecnocráticas y las prácticas hegemónicas pueden ser sucedáneos de las prácticas deliberativas, que suelen son sospechadas de ingenuas idealizaciones dado que, obviamente, nadie ha visto ni verá a una comunidad entera (¿cuáles son sus límites??), arracimada en torno al árbol de la deliberación. Es por ello que, en una época en la que se combinan el decisionismo político y el populismo antiilustrado, es necesario revisar los fundamentos de la deliberación y seńalar sus vínculos insoslayables con la democracia. Dado que además la deliberación no puede ser erróneamente identificada con un procedimiento teórico o un saber de ilustrados, es necesario basarla en el ámbito más amplio y comprensivo de las prácticas comunicativas.

Este es el camino elegido por Habermas, quien ancla la política, por un lado, en la ética comunicativa y por otro en el ámbito jurídico-legal, aunque sin subsumirla en ellos y manteniendo así la autonomía del campo político democrático centrado en la soberanía popular discursivamente redefinida.

Los principios de la ética del discurso o ética comunicativa ${ }^{5}$, que constituyen, a su vez, los fundamentos de la política deliberativa, son el principio del discurso (D) y el principio de universalización de intereses (U). Básicamente, la democracia deliberativa sostiene que los conflictos prácticos deben dirimirse intersubjetivamente mediante argumentos basados en razones, de modo tal de tener en cuenta los intereses y perspectivas de todos los afectados presentes y futuros por la situación del caso. La generalización de intereses supone un proceso de intercambios y aprendizajes mutuos mediante los cuales se busca modificar las respectivas posiciones a fin de lograr consensos sobre cuestiones públicas racionalmente fundados. Por cierto que éstos no siempre pueden ser alcanzados y que nunca son definitivos y por ello la democracia deliberativa reconoce la legitimidad de otros principios en el campo político, por ejemplo, la negociación.

La deliberación democrática opera como un contrafáctico y presupone siempre una situación idealizada: que todos los afectados por la situación objeto de la argumentación entran a ella con igual derecho a defender sus intereses y valores libres de toda coacción y acuerdan lograr entendimientos fundados en buenas razones. Ello no es motivo - como algunos críticos pretenden - para su descalificación por "idealista" e impracticable, dado que se trata de un procedimiento que es a la vez condición de posibilidad y de legitimación de una opinión y voluntad política racionalmente fundadas y un patrón de enjuiciamiento normativo de las acciones sociales justas, pero nunca un modelo o una receta para la toma del poder. La lucha social y política corre por un andarivel y la situación ideal del discurso por otro, pero sin ésta, aquélla corre el riesgo de disolverse en la protesta, el gesto exasperado, la propuesta desarticulada, el movimiento sin institucionalización y la expresión de meras particularidades, y de carecer, además, de un procedimiento y criterio de juicio normativo para distinguir lo justo de lo injusto.

Tampoco el principio del discurso (D) debe ser confundido con un principio científico-teórico de cuño eurocéntrico. Por el contrario, se trata aquí de la capacidad comunicati-

\footnotetext{
5 Dado que la palabra 'discurso' ha sido frecuentemente mal interpretada, Habermas ha preferido referirse a su teoría como ética comunicativa, eliminando el equívoco respecto a un posible sesgo teórico e intelectualista del término discurso.
} 
va inherente a todo ser humano capaz de lenguaje y acción, de la dimensión universal de la pragmática, por medio de la cual se logran acuerdos fundados en buenas razones.

En el transcurso de la situación discursiva se construye un sistema de expectativas mutuas basadas en interpelaciones, respuestas e intercambios. Pero a diferencia de los diálogos propios de los mundos de la vida, los discursos prácticos continúan mediante procedimientos reflexivos el interjuego de reconocimiento, confianza y expectativas mutuas presentes en las conversaciones ordinarias.

Ambos principios son complementarios. Generalizar intereses no significa universalizar una particularidad ni limitarse a las opciones dadas, puesto que se trata de un proceso por el cual se producen transformaciones en el sistema existente de valores y/o intereses con la única restricción de no socavar los principios de igual respeto, igual consideración e igual trato. En este sentido, el principio de universalización es la forma en que se expresa la utopía emancipatoria en sociedades en las cuales son las razones y argumentos de los propios participantes la piedra de toque de las decisiones políticas. Ambos ofrecen una alternativa para dirimir conflictos prácticos, generar consenso y promover la construcción de esferas públicas como un ámbito de instituciones mixtas, formales e informales y de fronteras móviles y flexibles, congruentes, justas y eficaces, en contextos complejos en los cuales debe garantizarse el pluralismo valorativo y disminuir la desigualdad. ${ }^{6}$

Escuchar al otro y ponerse en su lugar, distanciarse de sí mismo para constituirse en otro para sí, modificar la propia posición, anticipar las consecuencias de las decisiones tomadas, imaginar alternativas, son algunos de las acciones discursivas que se realizan en los procesos de deliberación. Como se ve, estos procedimientos no tienen nada de 'formales', puesto que involucran debates y tomas de posición respecto a cuestiones sustantivas referidas a actitudes, intereses y valores. Pero dichas decisiones deben fundarse en buenas razones, en razones que todos podrían aceptar sin vulnerar los principios de igual respeto, trato y consideración para todos. Las razones que deben circular e intercambiarse pueden ser tanto prácticas como teóricas, jurídico-legales, como éticas, pragmáticas o estrictamente políticas.

Finalmente, ¿para qué participar? Sin duda que no hay una única respuesta. Se participa para afirmar el sentido de pertenencia y afianzar la propia identidad, para lograr mayor bienestar, para luchar por los derechos y para reclamar justicia. Para afirmarnos como sujetos autónomos y soberanos. Todos estos sentidos están vinculados y constituyen aspectos o dimensiones de la ciudadanía. Si, en términos generales, el objetivo de la participación democrática es mejorar las condiciones de vida reduciendo desigualdades, el cómo tiene que ser acorde con los mismos y debe haber concordancia entre la autonomía (o heteronomía) de medios y fines. Si el objetivo es lograr la igualdad de resultados, el cómo puede ser objeto de decisiones heteronómas. Pero si el objetivo es la potenciación de las propias capacidades para reducir las desigualdades injustas, entonces el cómo debe incluir procesos de participación que respeten tanto el principio de universalización de intereses como el principio de deliberación y argumentación: no nos transformaremos en individuos libres para reducir la desigualdad si carecemos de igual posibilidad y capacidad de tomar decisiones autónomamente.

${ }^{6}$ Tomo esta triple caracterización (contextos de complejidad, pluralismo valorativo y justicia social) de J.Bohman (1996). 
En síntesis, las políticas (públicas) definidas exclusivamente por el Estado, pensadas exclusivamente con criterios locales, orientadas a la obtención de productos y resultados y decididas mediante prácticas democráticas restringidas, carentes de consensos fundados en razones y mediante procesos deliberativos, por cierto que no contribuirán a una auténtica democracia - por más que pretendan autolegitimarse en la apelación a la participación popular. Muy especialmente, las políticas públicas que no promueven la construcción de lazos de confianza racional se verán condenadas al fracaso porque sin el humus ético de dichas virtudes todo diálogo, conversación y procedimiento deliberativo carecerá de la credibilidad necesaria para generar acciones colectivas y reforzar el lazo social.

\section{Referências Bibliográficas}

Bohman, James - Public Deliberation, Pluralism, Complexity and Democracy. Cambridge, Mass: MIT Press, 1996. Foley, Michael; Edwards, Bob; Diani, Mario - "Social Capital Reconsidered". In Idem (eds.) Beyond Tocqueville, Civil Society and the Social Capital Debate in Comparative Perspective. Hanover: TUFTS University, 2001.

Habermas, Jurgen - Escritos sobre moralidad y eticidad, Barcelona: Paidós, 1991.

Hardin, Russel - "Do we trust in government?" In Warren, Mark (ed.) Democracy \& Trust. Cambridge, Mass: Cambridge University Press, 1999.

Offe, Claus - "How can we trust our fellow citizens?, In Warren, Mark (ed.) Democracy \& Trust. Cambridge, Mass: Cambridge University Press, 1999.

Reigadas, Maria Cristina - "Modernización e identidad en América Latina. El argumento de la inferioridad", Revista de Filosofía Latinoamericana y Ciencias Sociales, Asociación de Filosofía Latinoamericana y Ciencias Sociales. Segunda Epoca, Año XXV, No 22, 2000.

Reigadas, María Cristina - "Capital social y democracia: el caso argentino", Revista de Estudos em Sociología, Vol.10, No 1/2, 2004, pp. 65-83.

Seligman, Adam - The problem of trust. Princeton, N.J: Princeton University Press, 1997.

Warren, Mark - "Introduction". In Warren, Mark (ed.) Democracy \& Trust. Cambridge: Cambridge University Press, 1999.

\section{Informes y Encuestas}

Informe sobre Capital Social del Banco Mundial para América Latina y el Caribe, 2002.

Encuesta "Democracia, corrupción y clientelismo", Universidad de Belgrano, Argentina, 2003.

Informe de Participación Ciudadana en América Latina, RID, GADIS y FINES, Buenos Aires, 2005.

PNUD/Argentina, Informe para el Desarrollo Humano, 2005.

PNUD, Democracia en América Latina, 2005. 